\title{
Correlation between efficacy and skin rash occurrence following treatment with the epidermal growth factor receptor inhibitor cetuximab: A single institution retrospective analysis
}

\author{
MICHELE ORDITURA ${ }^{1}$, FERDINANDO DE VITA ${ }^{1}$, GENNARO GALIZIA ${ }^{2}$, EVA LIETO $^{2}$, \\ LOREDANA VECCHIONE $^{1}$, FABIANA VITIELLO ${ }^{1}$, ERIKA MARTINELLI ${ }^{1}$ and FORTUNATO CIARDIELLO ${ }^{1}$ \\ ${ }^{1}$ Division of Medical Oncology, ${ }^{2}$ Division of General Surgery, 'F. Magrassi - A. Lanzara’ Department of Clinical \\ and Experimental Medicine, Second University of Naples School of Medicine, Naples, Italy
}

Received November 26, 2008; Accepted December 30, 2008

DOI: 10.3892/or_00000319

\begin{abstract}
Several trials show a relationship between skin toxicity, response rate, and overall survival in cetuximabtreated patients. We analyzed our database to evaluate the importance of skin rash as a surrogate marker of favorable outcome in cancer patients referred to our institution in the last three years. We retrospectively analyzed 90 cetuximabtreated patients: 57 colon cancer patients, 10 NSCLC patients, 14 locally advanced esophageal cancer patients, and 9 miscellaneous. A significant correlation was observed between skin rash and response to therapy. Skin rash was experienced by $93 \%$ of PR and $100 \%$ of CR patients. The mean TTP was 184 days in patients showing skin rash and 94 days in patients without skin rash, respectively. On multivariate analysis, skin rash was demonstrated to be the only independent prognostic variable with regard to TTP. Patients who did not develop skin rash had a 2-fold greater likelihood to manifest tumor progression significantly earlier than patients who developed skin rash. In our series, a statistically significant correlation between rash, response rate, and TTP was demonstrated in 90 cetuximab-treated patients. Skin toxicity was confirmed as the only clinical variable able to predict the response to cetuximab.
\end{abstract}

\section{Introduction}

The epidermal growth factor receptor (EGFR) is a transmembrane glycoprotein that consists of an extracellular

Correspondence to: Dr Michele Orditura, Division of Medical Oncology, 'F. Magrassi - A. Lanzara' Department of Clinical and Experimental Medicine, Second University of Naples School of Medicine, c/o II Policlinico, Via S. Pansini, 5, 80131 Naples, Italy E-mail: michele.orditura@unina2.it

Key words: epidermal growth factor receptor, cetuximab, skin rash, predictive factor domain, a hydrophobic transmembrane domain, and an intracellular region containing the tyrosine kinase (TK) domain. EGFR can be activated by numerous ligands, such as epidermal growth factor (EGF), transforming growth factor $\alpha$ (TGF- $\alpha$ ), amphiregulin, epiregulin, neuregulin and betacellulin, while its activity can be inhibited by blocking the extracellular domain (using the monoclonal antibodies, $\mathrm{mAb}$ ) or the intracellular domain (using small molecules). EGFR is overexpressed in several solid human tumor types, such as head and neck, breast, colorectal, ovarian, lung, bladder, glioblastoma, esophageal, and pancreatic cancer (1).

Cetuximab (Erbitux, C225; ImClone System Inc., New York, NY; BMS, Merck Serono), a chimeric monoclonal IgG1, blocks the extracellular domain of EGFR, competitively inhibiting the physiologically binding of its ligands. Its affinity for EGFR is twice as much as that of EGF and TGF- $\alpha$ (2). Cetuximab promotes receptor internalization and its subsequent degradation. This receptor down-regulation results in both reduction of EGFR availability on cell surface and cell cycle inhibition. Furthermore, it has an indirect antitumor activity due to an antibody-dependent cell mediated cytotoxicity (ADCC) exerted by monocytes and natural killer cells (3).

Cetuximab, in combination with irinotecan or as a singleagent, has been licensed by both the Food and Drug Administration and the European Medicines Agency for the treatment of advanced, EGFR-positive colorectal cancer patients following failure of 5-fluorouracil-, oxaliplatin- and irinotecanbased chemotherapy. It has also been approved in association with radiotherapy in locally advanced or unresectable head and neck squamous cell carcinoma (HNSCC) and alone in locally advanced or metastatic pretreated HNSCC patients.

The major adverse effect of cetuximab, well described in clinical trials, is the development of skin toxicity, manifested by rash and xerosis, mainly occurring on the face, neck and upper torso. Sometimes patients develop xerophthalmia, paronychial cracking and epidermolysis.

The mechanism of this side effect is not clear even if several studies underline the role of homodimer EGFR inhibition on skin cell surface by the chimeric antibody (4).

Several cetuximab-based clinical studies show a relationship between skin toxicity, response rate, and overall survival. 
Based on this background, we conducted a retrospective analysis to evaluate the importance of skin rash as a surrogate marker of favorable outcome in cetuximab-treated cancer patients referred to our institution in the last three years.

\section{Patients and methods}

We retrospectively analyzed 90 cetuximab-treated patients (pts): 57 colon cancer pts, 10 non-small cell lung cancer (NSCLC) pts, 14 locally advanced esophageal cancer pts, and 9 miscellaneous pts (i.e., head and neck squamous cell carcinoma and gastric cancer). Most of them were enrolled in clinical trials, namely, NSCLC pts were part of the CALC-1 trial (5), esophageal pts were part of the B152 study (6), and, among the 57 colon cancer pts, 17 were part of the EPIC (7), MABEL (8), EVEREST (9), CRYSTAL (10), EMR 62 202045 (11) trials. All colorectal cancers were EGFR positive by immunohistochemistry (IHC), with a score ranging from $1+$ to $3+$. Clinical trials were conducted in according to Good Clinical Practice requirements. Patient characteristics are summarized in Table I. The following clinical parameters were recorded in all pts: age, gender, site of primary cancer, number of metastatic organs, number of line of therapy, skin toxicity, and best response (according to RECIST criteria) (Table I).

Rash definition. Cetuximab-induced skin rash was classified according to NCI-CTC version 2.0, using the following criteria: grade 1: macular or papular eruption or erythema without associated symptoms; grade 2: macular or papular eruption or erythema with pruritus or other associated symptoms covering $<50 \%$ of body surface or localized desquamation or other lesions covering $<50 \%$ of body surface area; grade 3: symptomatic generalized erythroderma or macular, papular or vesicular eruption or desquamation covering $\geq 50 \%$ of body surface area; grade 4 : generalized exfoliative dermatitis or ulcerative dermatitis.

Statistical analysis. Statistical analysis was carried out using the SPSS statistical package (SPSS Inc., Chicago, IL). In all analyses, the significance level was specified as $\mathrm{p}<0.05$. Single and multiple linear regression estimated the relationship between rash grade (skin toxicity) and the other variables. By estimating the coefficients of the linear equation involving one or more independent variables, this analysis was also used to analyze the significance of each variable to predict the best response.
Table I. Patient charateristics.

No. of patients

\begin{tabular}{lcl}
\hline Total & 90 & \\
Gender & & \\
Male & 64 & \\
Female & 26 & \\
Age, years & & \\
$\quad$ Median & 63.2 & \\
Range & $24-81$ & \\
Primary cancer & & \\
Colorectal & 57 & 63 \\
Esophageal & 14 & 15.5 \\
Lung & 10 & 11.5 \\
Other & 9 & 10
\end{tabular}

No. of organs with metastasis

0

1

2

3

4

Line of therapy

Pre-operative 14

15.5

I

II

25.5

20

28.8

III

10

Skin toxicity

Absent

24.4

G1

G2

G3

40

31.1

G4

4.4

Best response

Progressed $17 \quad 18.8$

SD

54.4

PR

CR

Table II. Multiple regression related to response rate in 90 cancer patients treated with cetuximab.

\begin{tabular}{|c|c|c|c|c|c|}
\hline Variable & Coefficient & Standard error & $\mathrm{t}$ & $\mathrm{r}$ & $\mathrm{p}$ \\
\hline Gender & 0.1135 & 0.1699 & 0.668 & 0.0384 & 0.506 \\
\hline Age & -0.0011 & 0.0062 & -0.186 & -0.0944 & 0.853 \\
\hline Primary & -0.0339 & 0.077 & -0.436 & -0.1090 & 0.664 \\
\hline Line & -0.1381 & 0.1730 & -0.798 & 0.0038 & 0.427 \\
\hline Metastatic organs & -0.0519 & 0.0966 & -0.537 & 0.0342 & 0.592 \\
\hline Skin rash & 0.4113 & 0.0947 & 4.344 & 0.4690 & 0.001 \\
\hline
\end{tabular}




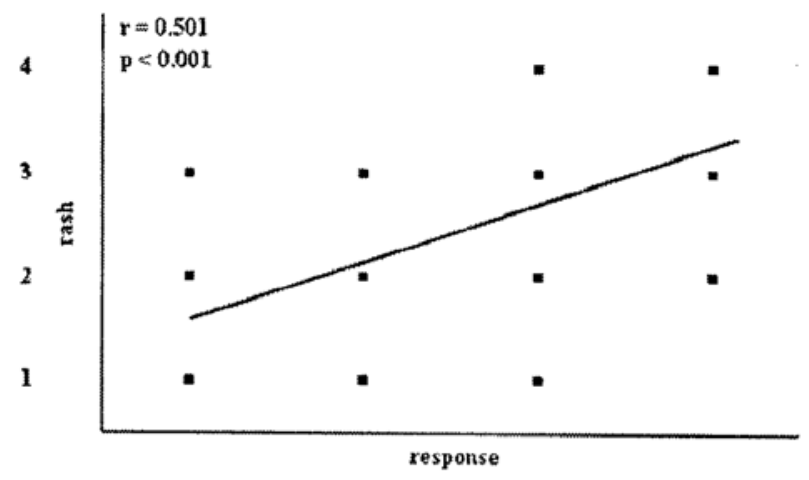

$\begin{array}{lcccc} & \text { PD } & \text { SD } & \text { PR } & \text { CR } \\ (n=17) & (n=49) & (n=16) & (n=8) \\ \text { absent } & 12 & 9 & 1 & - \\ \text { G1 } & 4 & 22 & 7 & 3 \\ \text { G2 } & 1 & 18 & 6 & 3 \\ \text { G3 } & - & - & 2 & 2\end{array}$

Figure 1. Linear regression between occurrence of skin rash and its toxicity grade and response to therapy. Better reponses were significantly correlated with highest grades of skin toxicity. G1-G4, different grades of skin toxicity; $\mathrm{PD}$, progression disease; $\mathrm{SD}$, stable disease; PR, partial response; $\mathrm{CR}$, complete response.

The time to tumor progression (TTP) was calculated from the start of cetuximab-based chemotherapy to the evidence of tumor progression, in order to assess the best response rate. Since 14 esophageal cancer patients received radiochemotherapy as neoadjuvant treatment, univariate and multivariate analyses related to TTP were limited to the remaining 76 patients receiving chemotherapy with intention to treat.

Rates of TTP were estimated by the Kaplan-Meier method and compared by the log-rank test; p-values and hazard ratios (HR) with $95 \%$ confidence interval (CI) are provided. The independent significance of prognostic variables was determined by multivariate analysis, using Cox's proportional hazards model.

\section{Results}

A total of 90 patients, 64 males and 26 females with a median age of 63.2 years, was analyzed. Most of them had stage IV colorectal cancer (57), 10 had stage IV NSCLC, 14 had locally advanced esophageal cancer, and 9 were mixed (HNSCC and gastric cancer). Among the 90 pts, the 14 esophageal cancer pts did not have metastatic cancer whereas the other 76 pts had a systemic disease, mainly localized to the liver and lung. In the colorectal cancer population, cetuximab was administered as first-line treatment, in combination with FOLFIRI; as second-line, in combination with irinotecan, after first-line oxaliplatin-, fluoropyrimidine basedchemotherapy failure; as third-line, in combination with irinotecan, after irinotecan-based therapy failure. In stage IV NSCLC pts, cetuximab was administered as first-line in combination with gemcitabine. Finally, it was administered as preoperative therapy in combination with FOLFOX-4 and radiotherapy in esophageal cancer pts.

The overall response rate, i.e., complete response (CR) plus partial response (PR), was $26.5 \%$, while the disease control rate, i.e., CR plus PR plus stable disease (SD), was
Table III. Univariate analysis related to TTP in 76 cancer patients treated with cetuximab.

\begin{tabular}{|c|c|c|c|c|}
\hline Variable & $\begin{array}{c}\text { No. of } \\
\text { patients }\end{array}$ & HR & $\begin{array}{c}95 \% \mathrm{CI} \\
\text { of HR }\end{array}$ & $\mathrm{p}$ \\
\hline Sex & & 0.76 & $0.47-1.24$ & 0.276 \\
\hline M & 53 & & & \\
\hline $\mathrm{F}$ & 22 & & & \\
\hline Age $^{a}$ & & 0.85 & $0.53-1.34$ & 0.488 \\
\hline$<66$ years & 38 & & & \\
\hline$>66$ years & 38 & & & \\
\hline Primary & & 0.72 & $0.38-1.23$ & 0.210 \\
\hline Colon & 57 & & & \\
\hline Others & 19 & & & \\
\hline Line & & $/ /$ & // & 0.560 \\
\hline First & 23 & & & \\
\hline Second & 18 & & & \\
\hline Third & 26 & & & \\
\hline Fourth & 9 & & & \\
\hline Line & & 0.95 & $0.57-1.56$ & 0.952 \\
\hline First & 23 & & & \\
\hline Others & 53 & & & \\
\hline No. of metastatic & & $/ /$ & $/ /$ & 0.409 \\
\hline
\end{tabular}

organs

$\begin{array}{lr}\text { One } & 31 \\ \text { Two } & 31 \\ \text { Three } & 11 \\ \text { Four } & 3\end{array}$

Metastatic organs

$0.76 \quad 0.46-1.21 \quad 0.251$

1 vs.

$>1$

/l $\quad$ /l

0.001

Skin toxicity

Absent

G1 31

G2 23

G3

$0.47 \quad 0.19-0.69$

0.002

Skin toxicity

No

21

Yes

55

Skin toxicity

$0.93 \quad 0.53-1.62$

0.798

G1

31

G2

23

aMedian value.

80.9\%; progression was observed in 17 pts. It is worth noting that most of the complete responses occurred in esophageal cancer pts (7/8), whereas only one CR was achieved in the colorectal cancer population. 


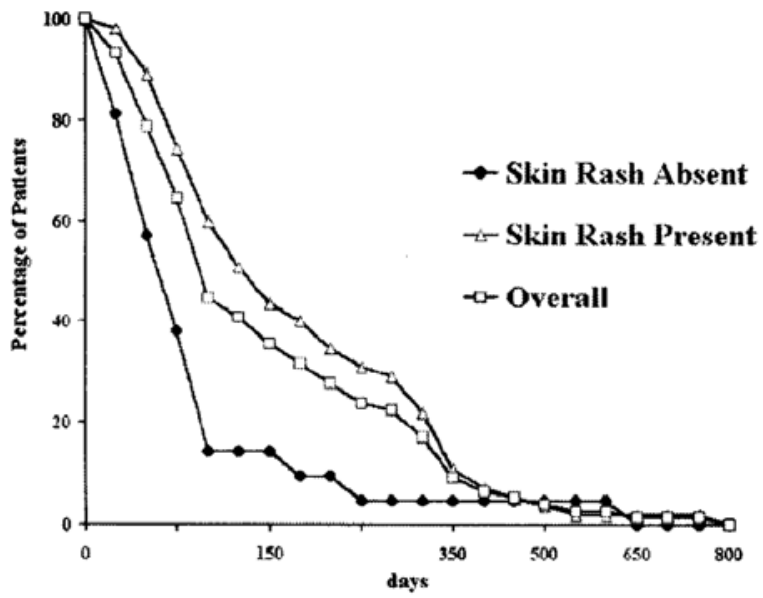

Patients at risk

$\begin{array}{lrrrrrrrr}\text { Overall } & 76 & 49 & 27 & 17 & 7 & 3 & 1 & 0 \\ \text { Absent } & 21 & 8 & 3 & 1 & 1 & 1 & 0 & 0 \\ \text { Present } & 55 & 41 & 24 & 16 & 6 & 2 & 1 & 0\end{array}$

Figure 2. Time to progression according to the skin rash occurrence. For comparison, TTP of all patients is shown.

Sixty-eight patients $(75.5 \%)$ experienced skin rash with different grades of toxicity. However, none of the patients showed grade 4 skin toxicity requiring cetuximab discontinuation. The appearance of skin rash was shown to have no relation with age, gender, site of primary cancer, number of metastatic organs and line of therapy (as analyzed by linear regression). Conversely, a significant correlation was observed between occurrence of skin rash and response to therapy. Of the 17 pts who did not have a skin rash, 12 showed disease progression; on the other hand, a skin rash was experienced by $93 \%$ of PR pts and $100 \%$ of CR pts (Fig. 1). Interestingly, multiple regression identified no other variable capable to predict the response to therapy with cetuximab (Table II).

All 76 patients but one undergoing chemotherapy with intention to treat progressed (Fig. 2). The mean time to tumor progression was $157 \pm 17$ days (95\% CI 123-191 days); median TTP was $92 \pm 7$ days (95\% CI 79-105 days). On univariate analysis, only skin rash was demonstrated to correlate with time to progression (Table III). Patients who developed skin rash were shown to experience a longer time to progression than patients who did not develop a rash. Specifically, the mean TTP was 184 days in patients showing skin rash and 94 days in patients without skin rash, respectively; that corresponded to a $53 \%$ reduction in the risk to have a short time to progression (HR, 0.47; 95\% CI, 0.53-1.62). No statistical differences were noted among patients showing different grades of skin toxicity (Table II). On multivariate analysis, skin rash was demonstrated to be an independent prognostic variable with regard to time to progression. Patients who did not develop skin rash had a 2-fold greater likelihood to manifest tumor progression significantly earlier than patients who developed skin rash (Table IV).

No other variable was demonstrated to show a correlation with TTP on univariate and multivariate analyses (Tables III and IV).

\section{Discussion}

EGFR expression is an independent prognostic indicator of disease recurrence and poor survival in colon and gastric cancer patients $(12,13)$. Likewise, NSCLC patients overexpressing EGFR have been demonstrated to have a worse outcome (14). Furthermore, current evidence suggests no association between a high EGFR cell surface expression and cetuximab response in colorectal cancer patients (15-19). Particularly in colorectal cancer, recent studies suggest that mutations of K-RAS gene are associated with nonresponsiveness to cetuximab, while amphiregulin and epiregulin overexpression may be markers of response (20-24).

While trials are ongoing to validate the role of these biomarkers, the important question of defining the patient population who will benefit from cetuximab therapy still remains unanswered.

Skin rash represents the only clinical marker of response to cetuximab treatment. In five phase II studies, patients who developed an acne-like rash were shown to survive longer than those who did not develop a rash, suggesting that skin toxicity may be a relevant surrogate of cetuximab clinical efficacy (17-18,24-26). The BOND trial reported higher response rates in patients experiencing skin toxicity compared with pts without skin rash (25.8 vs. $6.3 \%$, respectively, in the combination therapy group, $\mathrm{p}=0.005$ ) (15). Lenz et al obtained, in a phase II study of 346 colorectal cancer (CRC) pts treated with cetuximab and refractory to irinotecan, oxaliplatin and fluoropyrimidine, a partial response in 7, 17 and 20\% of pts with grade 1, 2 and 3 skin rash, respectively (22). These two studies and one reported by Salz et al (16) showed a longer survival in patients with severe skin toxicity compared with those without rash.

In contrast, results from the EVEREST study stressed the inability of skin rash to predict the outcome of

Table IV. Multivariate analysis related to TTP in 76 cancer patients treated with cetuximab.

\begin{tabular}{|c|c|c|c|c|c|}
\hline Variable & Coefficient & Standard error & Hazard rate & $95 \%$ CI of HR & $\mathrm{p}$ \\
\hline Gender & 0.2396 & 0.2642 & 1.27 & $0.75-2.12$ & 0.364 \\
\hline Age & 0.0073 & 0.0101 & 1.00 & $0.98-1.02$ & 0.464 \\
\hline Primary & 0.1421 & 0.1297 & 1.15 & $0.89-1.48$ & 0.273 \\
\hline Line & 0.0021 & 0.1141 & 1.00 & $0.80-1.25$ & 0.985 \\
\hline Metastatic organs & 0.0893 & 0.1660 & 1.09 & $0.79-1.51$ & 0.590 \\
\hline Skin rash & 0.7418 & 0.2699 & 2.09 & $1.24-3.55$ & 0.005 \\
\hline
\end{tabular}


cetuximab-treated patients and demonstrated no association between K-RAS and skin toxicity (9). Also, Lièvre et al recorded in the multivariate analysis of the study a strong correlation between K-RAS mutation and progression, free survival, and overall survival, whereas skin rash was only associated with OS. This study also demonstrated no correlation between K-RAS status and skin rash (23).

In our retrospective analysis, a statistically significant correlation between rash, response rate, and time to progression was demonstrated in a series of 90 cetuximabtreated patients, of whom $>50 \%$ had advanced colorectal cancer, and most of them were enrolled into clinical trials. Skin toxicity was confirmed as the only clinical variable able to predict the response to cetuximab by multiple regression analysis (Table II).

In our series, a significant correlation between skin rash and time to progression was recorded, with an HR of 0.47 , which corresponds to a $53 \%$ reduction in treatment failure. Moreover, this benefit was independent of rash grade, whereas in other trials the advantage in terms of RR, OS and PFS was appreciable only in grade 2 or 3 rash. Therefore, while awaiting further studies conclusively addressing the prognostic role of K-RAS in cetuximab-treated patients, skin rash occurrence may be used as a clinical surrogate of response to cetuximab. An added value of this clinical parameter is that its evaluation is inexpensive; furthermore, when skin rash occurs, it appears early in the course of a cetuximab-based therapy thus allowing rapid response evaluation in the individual patient. Clearly, skin rash occurrence may permit possible identification of responders only once biologic therapy has been instituted. Thus, the need for indicators capable of identifying responders before starting biologic therapy remains and warrants further investigations.

\section{References}

1. Ciardiello F and Tortora G: EGFR antagonists in cancer treatment. New Engl J Med 358: 1160-1174, 2008.

2. Galizia G, Lieto E, De Vita F, Orditura M, Castellano P, Troiani T, Imperatore $\mathrm{V}$ and Ciardiello $\mathrm{F}$ : Cetuximab, a chimeric human mouse anti-epidermal growth factor receptor monoclonal antibody, in the treatment of human colorectal cancer. Oncogene 26: 3654-3660, 2007.

3. Iannello A and Ahmad A: Role of antibody dependent cellmediated cytotoxicity in the efficacy of therapeutic anti-cancer monoclonal antibodies. Cancer Metastasis Rev 24: 487-499, 2005.

4. Laux I, Jain A, Singh S and Agus DB: Epidermal growth factor receptor dimerization status determines skin toxicity to HERkinase targeted therapies. Br J Cancer 94: 85-92, 2006

5. Gridelli C, Mencoboni M, Carrozza F, Viganò MG, Gebbia V, Verusio C, Maione P, Gallo C, Perrone F and Ciardiello F: Cetuximab and gemcitabine in elderly or adult PS2 advanced non small cell lung cancer patients: the CALC1 randomized phase II trials. J Clin Oncol 26 (Suppl): abs. 8117, 2008.

6. De Vita F, Orditura M, Innocente R, Pinto C, Chiarion-Sileni V, Martinelli E, Vecchione L, Ancona E, Catalano G and Ciardiello F: Induction primary CT with FOLFOX-4 and Cetuximab followed by RT and Cetuximab in locally advanced esophageal cancer: Analysis of preliminary data from B152 trial. J Clin Oncol 26 (Suppl): abs. 15524, 2008.

7. Sobrero AF, Maurel J, Fehrenbacher L, Scheithauer W, Abubakr YA, Lutz MP, Vega-Villegas ME, Eng C, Steinhauer EU, Prausova J, Lenz HJ, Borg C, Middleton G, Kröning H, Luppi G, Kisker O, Zubel A, Langer C, Kopit J and Burris HA: EPIC: Phase III trial of cetuximab plus irinotecan after fluoropyrimidine and oxaliplatin failure in patients with metastatic colorectal cancer. J Clin Oncol 26: 2311-2319, 2008.
8. Wilke H, Glynne-Jones R, Thaler J, Adenis A, Preusser P, Aranda Aguilar E, Aapro M, Van Den Berg N, Eggleton S and Siena S: MABEL - A large multinational study of cetuximab plus irinotecan in irinotecan resistant metastatic colorectal cancer. J Clin Oncol 18 (Suppl): abs. 3549, 2006.

9. Tejpar S, Peeters M, Humblet Y, Gelderblom H, Vermorken J, Viret F, Glimelius B, Ciardiello F, Kisker O and Van Cutsem E: Phase I/II study of cetuximab dose-escalation in patients with metastatic colorectal cancer (mCRC) with no slight skin reactions on cetuximab standard dose treatment (EVEREST): Pharmacokinetic (PK), pharmacodynamic (PD) and efficacy data. J Clin Oncol 25 (Suppl): abs. 4037, 2007.

10. Van Cutsem E, Nowacki M, Lang I, Cascinu S, Shchepotin I, Maurel J, Rougier P, Cunningham D, Nippgen J and Köhne C: Randomized phase III study of irinotecan and 5-FU/FA with or without cetuximab in the first-line treatment of patients with metastatic colorectal cancer (mCRC): the CRYSTAL trial. J Clin Oncol 25 (Suppl): abs. 4000, 2007.

11. Cervantes A, Macarulla T, Martinelli E, Rodriguez-Braun E, Ciardiello F, Stroh C, Nippgen J, Baselga J and Tabernero J: Correlation of KRAS status (wild type [wt] vs. mutant [mt]) with efficacy to first-line cetuximab in a study of cetuximab single agent followed by cetuximab + FOLFIRI in patients (pts) with metastatic colorectal cancer (mCRC). J Clin Oncol 26 (Suppl): abs. 4129, 2008.

12. Galizia G, Lieto E, Ferraraccio F, De Vita F, Castellano P, Orditura M, Imperatore V, La Mura A, La Manna G, Pinto M, Catalano G, Pignatelli C and Ciardiello F: Prognostic significance of epidermal growth factor receptor expression in colon cancer patients undergoing curative surgery. Ann Surg Oncol 13: 823-835, 2006.

13. Galizia G, Lieto E, Orditura M, Castellano P, Mura AL, Imperatore V, Pinto M, Zamboli A, De Vita F and Ferraraccio F: Epidermal growth factor receptor (EGFR) expression is associated with a worse prognosis in gastric cancer patients undergoing curative surgery. World J Surg 31: 1458-1468, 2007.

14. Ciardiello F, De Vita F, Orditura M and Tortora G: The role of EGFR inhibitors in non-small cell lung cancer. Curr Opin Oncol: 16: 130-135, 2004.

15. Cunningham D, Humblet Y, Siena S, Khayat D, Bleiberg H, Santoro A, Bets D, Mueser M, Harstrick A, Verslype C, Chau I and Van Cutsem E: Cetuximab monotherapy and cetuximab plus irinotecan in irinotecan-refractory metastatic colorectal cancer. N Engl J Med 351: 337-345, 2004.

16. Saltz L, Meropol NJ, Loehrer PJ, Needle MN, Kopit J and Mayer RJ: Phase II trial of cetuximab in patients with refractory colorectal cancer that express the epidermal growth factor receptor. J Clin Oncol 22: 1201-1208, 2004.

17. Jonker DJ, O'Callaghan CJ, Karapetis CS, Zalcberg JR, Tu D, Au HJ, Berry SR, Krahn M, Price T, Simes RJ, Tebbutt NC, van Hazel G, Wierzbicki R, Langer C and Moore MJ: Cetuximab for the treatment of colorectal cancer. N Engl J Med 357: 2040-2048, 2007.

18. Chung KY, Shia J, Kemeny NE, Shah M, Schwartz GK, Tse A, Hamilton A, Pan D, Schrag D, Schwartz L, Klimstra DS, Fridman D, Kelsen DP and Saltz LB: Cetuximab shows activity in colorectal cancer patients with tumors that do not express the epidermal growth factor receptor by immunohistochemistry. J Clin Oncol 23: 1803-1810, 2005.

19. Hebbar M, Wacrenier A, Desauw C, Romano O, Cattan S, Triboulet JP and Pruvot FR: Lack of usefulness of epidermal growth factor receptor expression determination for cetuximab therapy in patients with colorectal cancer. Anticancer Drugs 17: 855-857, 2006.

20. Lièvre A, Bachet JB, Le Corre D, Boige V, Landi B, Emile JF, Côté JF, Tomasic G, Penna C, Ducreux M, Rougier P, Penault-Llorca F, Laurent-Puig P, et al: K-RAS mutation status is predictive of response to cetuximab therapy in colorectal cancer. Cancer Res 66: 3992-3995, 2006.

21. Khambata-Ford S, Garrett CR, Meropol NJ, Basik M, Harbison CT, Wu S, Wong TW, Huang X, Takimoto CH, Godwin AK, Tan BR, Krishnamurthi SS, Burris HA III, Poplin EA, Hidalgo M, Baselga J, Clark EA and Mauro DJ: Expression of epiregulin and amphiregulin and K-RAS mutation status predicte disease control in metastatic colorectal cancer patients treated with cetuximab. J Clin Oncol 25: 3230-3237, 2007.

22. Vallbohmer D, Zhang W, Gordon M, Yang DY, Yun J, Press OA, Rhodes KE, Sherrod AE, Iqbal S, Danenberg KD, Groshen S and Lenz HJ: Molecular determinants of cetuximab efficacy. J Clin Oncol 23: 3536-3544, 2005. 
23. Lièvre A, Bachet JA, Boige V, Cayre A, Le Corre D, Buc E, Ychou M, Bouché O, Landi B, Louvet C, André T, Bibeau F, Diebold MD, Rougier P, Ducreux M, Tomasic G, Emile JF, Penault-Llorca F and Laurent-Puig P: K-ras mutations as an independent prognostic factor in patients with advanced colorectal cancer treated with cetuximab. J Clin Oncol 26: 374-379, 2008.

24. De Roock W, Piessevaux H, De Schutter J, Janssens M, De Hertogh G, Personeni N, Biesmans B, Van Laethem JL, Peeters M, Humblet Y, Van Cutsem E and Tejpar S: KRAS wild-type state predicts survival and is associated to early radiological response in metastatic colorectal cancer treated with cetuximab. Ann Oncol 19: 508-515, 2008.
25. Lenz HJ, Van Cutsem E, Khambata-Ford S, Mayer RJ, Gold P, Stella P, Mirtsching B, Cohn AL, Pippas AW, Azarnia N, Tsuchihashi Z, Mauro DJ and Rowinskyet EK: Multicenter phase II and translational study of cetuximab in metastatic colorectal carcinoma refractory to irinotecan, oxaliplatin, and fluoropyrimidines. J Clin Oncol 24: 4914-4921, 2006.

26. Zhang W, Gordon M, Press OA, Rhodes K, Vallböhmer D, Yang DY, Park D, Fazzone W, Schultheis A, Sherrod AE, Iqbal S, Groshen S and Lenz HJ: Cyclin D1 and epidermal growth factor polymorphisms associated with survival in patients with advanced colorectal cancer treated with cetuximab. Pharmacogenet Genomics 16: 475-483, 2006. 